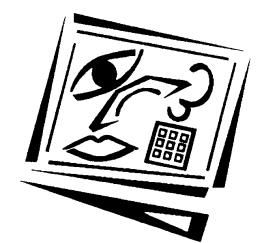

\title{
Enhancing teachers' ICT capacity for the 21st century learning environment: Three cases of teacher education in Korea
}

\author{
Hyeonjin Kim \\ Korea National University of Education \\ Hyungshin Choi \\ Chuncheon National University of Education \\ Jeonghye Han \\ Cheongju National University of Education \\ Hyo-Jeong So \\ Nanyang Technological University
}

\begin{abstract}
Korean teachers are generally considered well trained to integrate ICT into their teaching since the inception of the first IT Master Plan of Korea in 1996. However, the emergence and adoption of cutting-edge technologies create demands for evolving roles and competencies of teachers in the new knowledge society. Given this changing landscape of teacher education, the purpose of this paper is to explore new educational approaches to enhance teachers' ICT capabilities in the 21st century learning environment in Korea. The literature indicates that the new roles of teachers include new media literacy skills and adaptive expertise with efficiency and innovation. From this perspective, we examined three cases: (1) learning Scratch for computational and creative thinking, (2) learning robotics as emerging technology for convergent and divergent thinking, and (3) learning by design with ICT for systems thinking. The new approaches, such as focusing on thinking skills rather than technical skills, and providing various contexts different from ordinary classroom lessons, help teachers to develop adaptive expertise. On the other hand, participants in all three cases indicated difficulties in integrating new ideas, dealing with various course activities, and understanding unfamiliar design contexts in their comprehensive projects. For further studies, it is necessary to investigate learning processes and outcomes of teachers' learning with more depth and a larger number of cases and multiple sources of data to verify the potentials and challenges of these approaches more rigorously.
\end{abstract}

\section{Introduction}

ICT for education in Korea has shown progressive development and has matured over time since the inception of the first IT Master Plan for Korea in 1996 (Hwang, Yang \& Kim, 2010). While Korean teachers, in general, are considered to be well-equipped with ICT skills and knowledge for their current practices, their evolving roles and competencies in the rapidly changing society, coupled with the emergence and adoption of new technologies, have become a legitimate area of concern. That is, it is 
unclear how well teachers have been equipped to face the challenges and complexities of the teaching and learning in 21st century; and what directions should be taken to better prepare the new generation of teachers.

Given this changing landscape of teacher education, the purpose of this paper is to explore new educational approaches to enhance teachers' ICT capabilities in the 21st century learning environment, taking into account a critical examination of the current status of ICT education for teachers in Korea. Toward this end, three cases of teacher education in Korea are introduced and examined as to how the design and enactment of those courses contributed to enhancing teachers' ICT capacity for the changing needs of 21st century learning environments.

\section{Teacher ICT capacity for the 21st Century learning}

The nature of technologies for teaching and learning has become increasingly social, collective, and multi-modal since the emergence and rapid adoption of Web 2.0 and cloud technologies. Programs that are largely ICT skill-based are unlikely to prepare pre-service teachers to learn how to deal with the problem of complexity-making intimate connections amongst content, pedagogy, and technology (So \& Kim, 2009). This may suggest an immediate need to revisit assumptions underlying what we mean by necessary ICT competencies for teachers, and further, to redesign ICT-related modules in teacher education programs to provide pre-service teachers with opportunities for experiencing and developing new media literacy skills.

Based on the preceding discussion, we argue for the critical need to reframe teachers' ICT capacities from adaptive expertise perspectives. Since the seminal article on Two Courses of Expertise by Hatano and Inagaki (1986) and the conception of Preparation for Future Learning (PFL) by Bransford and Schwartz (1999), adaptive expertise has been used to explain the differences between novice and expert learners and further the importance of developing transferable knowledge and skills. Hammerness, DarlingHammond and Bransford (2005) suggest that the development of adaptive expertise involves two dimensions of expertise, efficiency dimension and innovation dimension:

The efficiency dimension means greater abilities to perform particular tasks without having to devote too many attentional resources to achieve them (p.361).

The innovation dimension involves moving beyond existing routines and often requires people to rethink key ideas, practices, and even values in order to change what they are doing (p.361).

They argue that the two dimensions are complementary, but can be antagonistic when they create conflicts. For instance, in the initial stage of learning innovative strategies and knowledge, teachers may experience their practices being less efficient than previous approaches. To be adaptive experts, however, they need to develop dispositions to perceive such initial experiences, not as a failure but as a valuable and productive process of learning.

Hammerness and colleagues (2005) suggest that helping teachers become adaptive experts needs three aspects of preparation. First, teacher educators need to help teachers to see teaching and learning in fundamentally different ways from what they might have learned from the "apprenticeship of observation" (Lortie, 1975) as school students. One of the important goals for teacher education is to help pre-service 
teachers view teaching as more than simply applying routine practices. In certain cases, this means that pre-service teachers need to reconstruct their established perceptions of teaching and learning in order to learn and adopt new ideas. Second, helping pre-service teachers teach more effectively means not only thinking like a teacher but also knowing for both understanding and enactment. Pre-service teachers often face problems of enactment. Effective enactment goes beyond the ability to apply routine practices. Instead, pre-service teachers need to be engaged in reflective practices where they have opportunities to practice and reflect on their own enactment in various contexts (Schön, 1983; Kim \& Hannafin, 2008). Problem-based learning, case-based learning or micro-teaching are examples of pedagogical approaches that help pre-service teachers become better prepared for effective enactment. The last aspect involves what they term "the problem of complexity", where teaching is viewed as process of developing habits of mind and practice to enact and reflect in an integrated and iterative way.

Adopting the efficiency and innovation dimensions of adaptive expertise, we argue that the prevalent models of teacher's ICT competencies may have more emphasis on the efficiency aspect than creating a room for innovative ideas to grow and mature. As mentioned earlier, typical ICT competency-stage models are of little use to the development of adaptive expertise, while such models may hold certain values for efficient teaching and diagnostic purposes. The new direction of ICT education for teachers lies primarily in the development of a set of adaptive and transferable knowledge and skills, so that teachers are better able to adapt to the challenging and complex nature of future learning environments. Therefore, the epistemic and pedagogical assumptions underlying the design of ICT courses for pre-service teachers have to be revisited a) to focus on doing with understanding where pre-service teachers are continuously exposed to better understand the complexities of teaching and learning with technology, and b) to develop systematic and creative thinking skills to grow innovative ideas.

\section{Sociocultural context: ICT and teacher education in Korea}

ICT has been integrated into educational contexts since the announcement of the first IT Master Plan for Korea in 1996 that promoted the use of e-portal (e.g., EDUNET), elearning (e.g., Cyber Home Learning System), and u-learning (e.g., Digital Textbooks). Recently, the Korean government (MEST, 2011) has announced the educational policy on smart learning for the new knowledge society. In tandem with the government's strategic movement toward smart learning, pre-service and in-service teacher training need to reflect the new paradigm of learning in their curriculum in terms of technology and pedagogy.

In-service teacher training in Korea has been conducted to support national policies on ICT for education since the late 1980s (Hwang et al., 2010). However, the Korean government has not formulated any centralised policy specific to ICT in education for pre-service teacher education. Instead, more agency and control were given to individual teacher education institutions (TEIs) and colleges of education in universities. Therefore, it can be said that the nature of ICT-in-education programs in Korea varies from institution to institution.

In Korea, national teaching certificates can be gained from several different types of institutions, including TEIs, universities, and graduate schools of education. Most 
TEIs, commonly named as a National University of Education, offer compulsory and elective courses about ICT-related topics (Park, Jun \& Kim, 2011). The compulsory course aims to enhance students' computer literacy through hands-on experiences with computers. Elective courses are designed to help pre-service teachers to be "digitally fluent", and to develop their ability to adapt and adopt new media in fast changing environments.

In this paper, we introduce and discuss three cases on ICT teacher training. The three cases were purposively selected to unpack how new approaches to building teachers' ICT capacities are formulated. All three cases are from the context of TEIs, where the authors are affiliated. The three authors in this paper participated in each case as an instructor.

\section{Case 1: Learning Scratch for computational and creative thinking}

The first case is a course is offered by Chuncheon National University of Education (CcNUE), which was founded in 1939 for elementary school teacher education. The course "Computer Practice" is designed to help pre-service teachers to be "digitally fluent" by managing information and creating teaching materials. The course is required for all third-year students at CcNUE. Previously, this course focused on teaching computer programming knowledge and skills based on traditional programming languages. The rationale for selecting computer programming is that computer programming supports the development of higher-order thinking skills such as computational thinking and problem-solving skills (Papert, 1980; Resnick et al., 2009; Wing, 2006). In addition, computer programming provides pre-service teachers with opportunities to reflect on their own thinking process. Consequently, pre-service teachers are expected to become more media-fluent by designing, creating, and expressing themselves with digital technologies.

\section{Learning goal}

Despite the benefits underlying computer programming, pre-service teachers often find it too difficult to master the syntax of programming languages. In 2008, the instructors for this course redesigned it using Scratch in order to overcome this issue. Scratch is an educational programming environment developed by the MIT Media Lab (2012). Scratch provides visual blocks, such as motion, looks, sound, pen, control, sensing, operators, and variables. Instead of writing program codes, Scratch users compose programs by dragging and stacking these building blocks. Scratch enables users to easily create media-rich content by incorporating graphics, sound, and animation.

The followings are the aspects of Scratch that meet the needs of this course. First of all, Scratch eliminates syntax errors by using graphical building-block programming. In addition, using Scratch moves the focus of the course from mastering programming languages to higher-order skills like problem-solving, creative thinking, logical reasoning, etc. Furthermore, programming with Scratch promotes learning by doing with understanding for the development of pre-service teachers' adaptive ability. In this rapidly changing environment, "knowledge alone is not enough" (Resnick, 2007; p.18), and therefore, pre-service teachers must be prepared to adjust themselves in response to the complexities in a fast-changing world. Lastly, Scratch stimulates students to come up with creative solutions by allowing playful experiments with 
program fragments. Scratch scaffolds for powerful ideas by making concepts more visible. Scratch has been incorporated into the computer practice course since the spring semester in 2009.

\section{Structure and method}

The computer practice course consists of nine modules followed by the orientation sessions. In the orientation module, pre-service teachers are introduced to what they can do with Scratch and become familiar with the Scratch user interface, the types of building blocks, and their basic functions. Each module focuses on a category of blocks and provides a small Scratch project, so that the participants can experiment with different types of coding blocks for the completion of the project. The modules guide the pre-service teachers to create animations, scrap books, games, quizzes, visual arts, music, dances, etc. In the last module, the students learn how to incorporate a Picoboard to capture the information outside of the computer. The Picoboard is a small hardware item that can be connected to a computer via a cable. Using the sensors on the board, the participants are able to implement the behaviours of the objects in the Scratch projects. The modules are designed for pre-service teachers to create various types of teaching and learning content that they can utilise in their future teaching contexts.

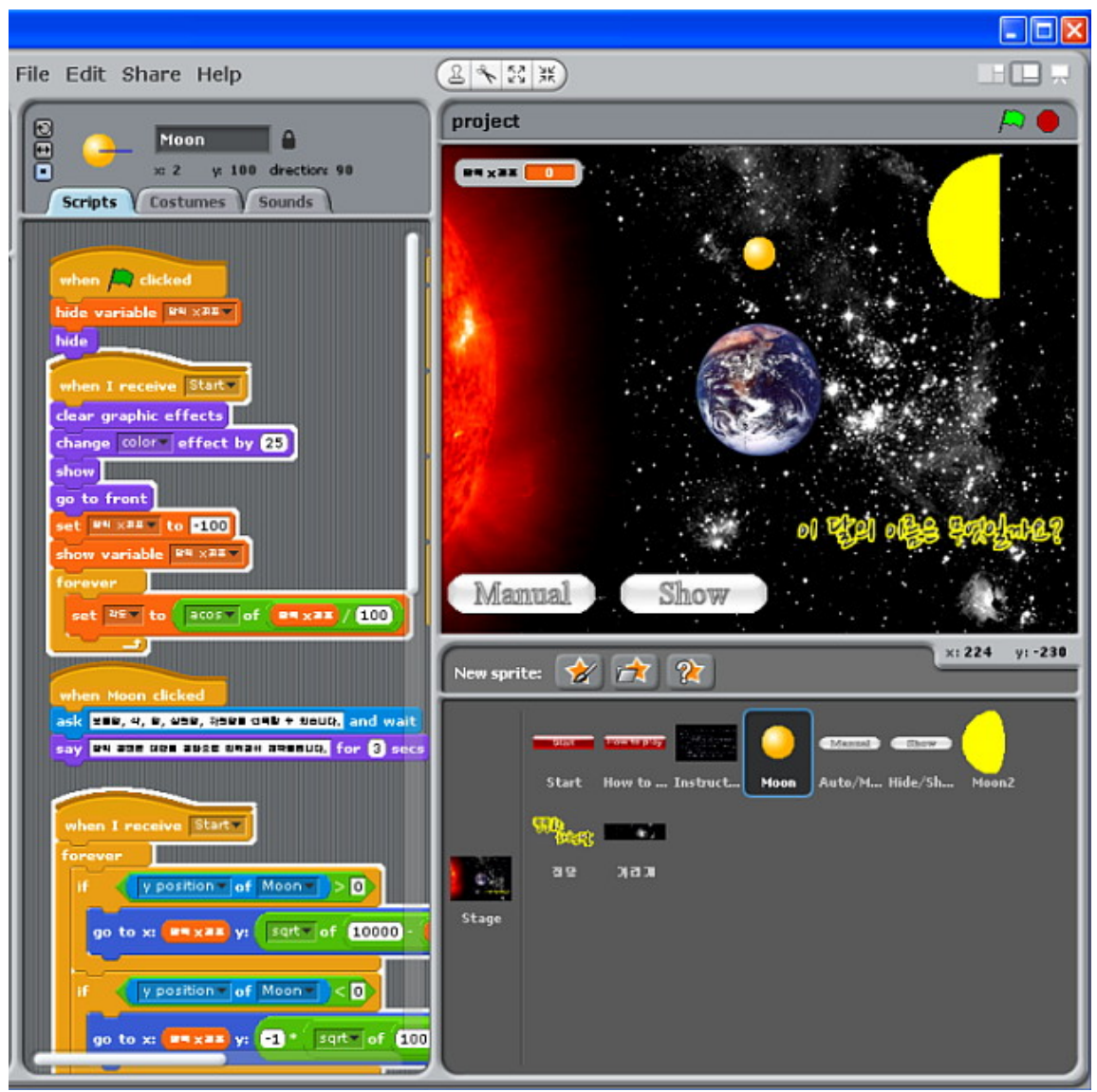

Figure 1: Screen shot of a pre-service teachers' final project (5th grade science) 
Upon the completion of nine modules, the participants design and implement their own project in groups of two. The pre-service teachers choose any topic in the elementary subjects, develop a lesson plan, and create learning content that can be used in the context of their lesson plan. At the end of the semester, each group presents their own project to the class, focusing on how the designed content helps their students achieve the learning goals, and how the group coducted the project with Scratch, including their planning and developing processes. For each presentation, two designated peers and the instructor provided feedback on what the best feature was and how they could improve their projects. Figures 1 and 2 show two examples of final projects developed by pre-service teachers.

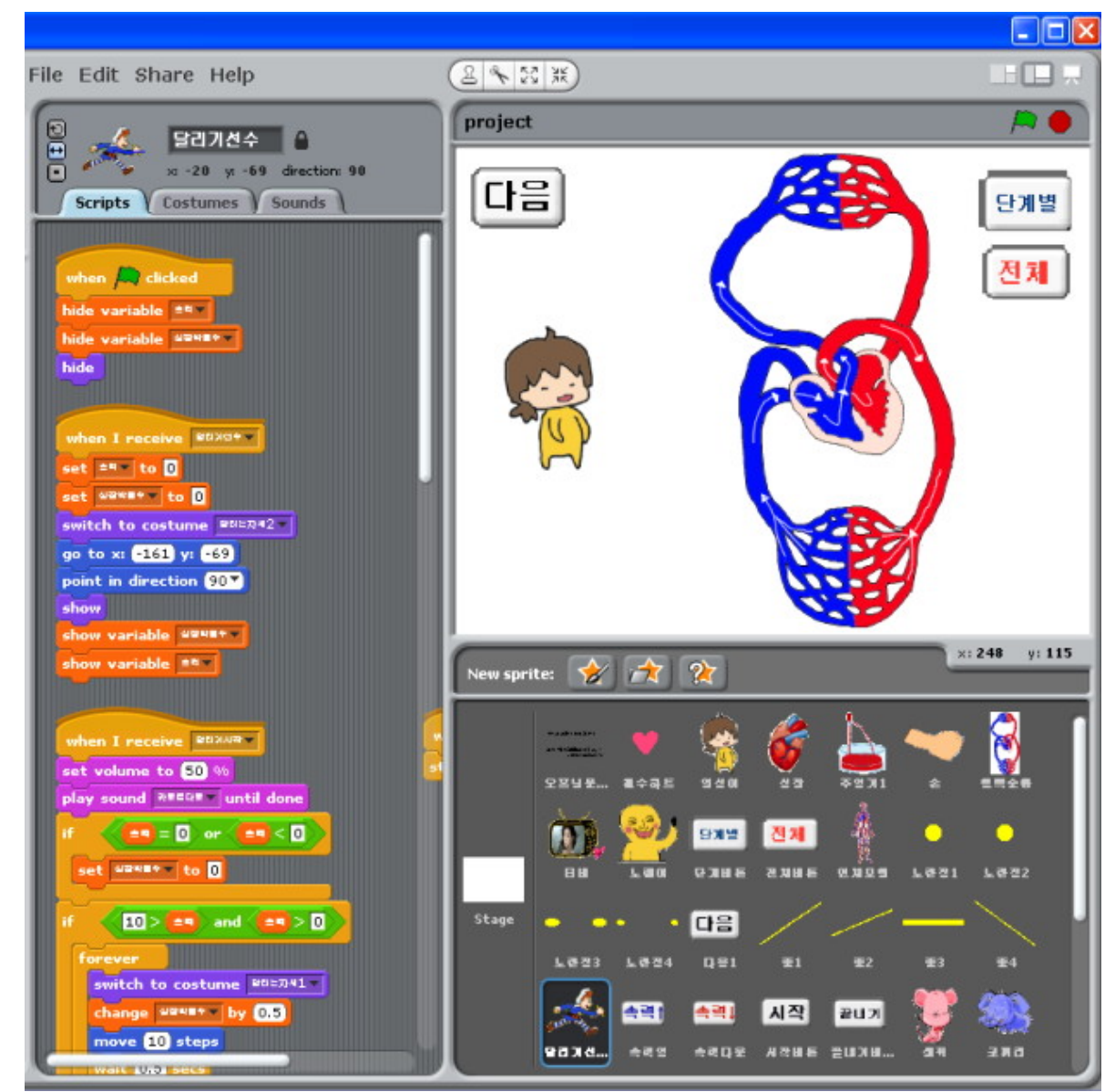

Figure 2: Screen shot of a pre-service teachers' final project (5th grade science)

\section{Evaluation}

In order to find out participants' perceptions toward the Scratch programming course, a survey was administered to the third-year pre-service teachers who took the computer practice course during the fall semester in 2010. In total, 133 pre-service teachers (100 female, 33 male) participated in the survey. The survey included two sections: learning skills and prospective use in future teaching. The learning skills 
section had five Likert scale items: Scratch programming helped me to improve (a) information and media literacy skills, (b) communication skills, (c) creative thinking skills, (d) problem solving skills, and (e) self-directed skills. The prospective use in future teaching section has two items: (a) I would like to use Scratch in my future teaching practices and (b) I believe that teaching Scratch programming to elementary students would help them to improve their learning skills. The Cronbach's alpha for the survey was .88 .

Participants' perception of acquiring learning skills through Scratch programming was overall positive (Mean=3.81, $\mathrm{SD}=.73)$. Among the five items, participants perceived that Scratch programming helped to improve creative thinking skills (Mean $=4.03$, $\mathrm{SD}=.91$ ), followed by problem solving skills (Mean=3.87, $\mathrm{SD}=.95)$, communication skills (Mean=3.79, SD=.94), self-directed skills (Mean=3.71, SD=.93), and information and media literacy skills (Mean=3.65, $\mathrm{SD}=.88$ ). They also responded that they would use Scratch to develop teaching materials in their future teaching practices (Mean=3.97, $\mathrm{SD}=.96$ ). The participants believed that teaching Scratch programming to elementary students would help them to improve learning skills (Mean=3.68, SD=.95).

In addition, the project artifacts were evaluated with five criteria: pedagogical design, technological design, creativity (originality), presentation skills, and promptness. Preservice teachers' creativity was evidenced in various manners. One team created a project to explain a mathematical concept (e.g., pi) in a simulation that participants could easily understand. Another team implemented music content that pre-service teachers could compose music by placing music notes. Lastly, another team presented famous paintings and had participants discover a hidden story in each painting. Also, pre-service teachers' adaptive expertise was indicated in several aspects. First, they brought authentic materials (e.g., news) into the content and these materials were connected with the subject of teaching. Second, pre-service teachers recorded their own voices and used these as voices of characters or sound effects of the content. Lastly, they incorporated different genres (i.e., music, movie clips, arts, stories, and games) into subject matters and showed their critical selection of different media.

\section{Lessons learned: Possibilities and challenges}

Unlike the traditional computer programming languages, Scratch helped pre-service teachers focus on what they could do with programming languages. Acquiring programming concepts has become implicit rather than explicit. Participants were delighted to have their own agency in the programming environment as they would not need to worry about debugging syntactic errors, and were able to create tangible products from the initial stage of the course. The variety of the projects pre-service teachers created showed how innovative and creative their approaches can be. In the course of learning with Scratch, they learned from each other about how to adapt the skills for prospective teaching, evidenced by the following qualitative comments given by students:

I used the skills I learned in this course in my practicum teaching. The students in my class loved it. I was thankful that I learned this new tool.

In this course, I created and presented content that I could use in an actual classroom. I was glad that through this project, I had an opportunity to recall what I had learned and utilised it. I learned from other teams' presentations. 
Programming was not easy, but I have gained some confidence that I can do. And I think I will use Scratch often in my prospective teaching.

I was very impressed by the creative approaches that other peer students took that I have never thought of. I learned a lot from watching other students' presentations.

In terms of expert adaptability, during this course pre-service teachers have experienced the integration and remixing of various media to represent new ideas. Scratch was used for pre-service teachers to create a room for innovative ideas. Yet, one of the challenges in this course is how to scaffold pre-service teachers' thinking processes since they need to pursue increasingly complex projects with the integration of new ideas. In addition, pre-service teachers need to consider how to use Scratch for creating educational content in pedagogically meaningful ways. This implies that instructors need to help pre-service teachers consider pedagogical impacts as well as design aspects.

\section{Case 2: Learning robotics as emerging technology for convergent and divergent thinking}

Cheongju National University of Education (CjNUE), founded in 1941, has built a reputation for ICT in teacher education as an award-winning institution in the contest for software development for teachers hosted by the Korea Education and Research Information Service in 2006-2009. The four courses on ICT in education are provided to enhance pre-service teacher's computer literacy through hands-on experiences with computers, and administrative ability with computer-based management systems. The topics range from the traditional ICT technologies to cutting-edge technologies, such as robotics for education.

There are mainly two kinds of educational robots: educational service robots and hands-on robots (Han, 2010). In particular, learning to teach with robotics is considered to be important to teachers in the 21st century because learning robotics in schools can facilitate students' knowledge building through active inquiry and constructive activities (Bransford, Brown \& Cocking, 2000). Learning to teach robotics can also help teachers to understand core concepts of computing (Klassner \& Anderson, 2003). In Korea, there has been increasing interest in robotics in elementary schools. About $43 \%$ of elementary schools in Korea were expected to offer robotics courses in their extra curriculum in 2010 (Hur, Choi \& Han, 2009). The Korean government also has formulated the nation-wide plan to expand robot-based learning through the "R-learning" program.

Among the four required courses on ICT in CjNUE, three courses focus on general computer literacy, while the other one is about Web-based Courseware Development and Programming, which is the focus of this case study. This particular course is designed to facilitate the development of convergent and divergent thinking. Furthermore, the course aims to help pre-service teachers learn by doing 'with understanding' to facilitate the development of adaptive expertise.

\section{Learning goal}

The learning goals of this course are to improve pre-service teachers' abilities for thinking and doing with creativity, by designing and programming web-based courseware, and to facilitate better understanding of the thinking process in authentic 
teaching practices. To achieve these goals, the pre-service teachers need to work on web-courseware projects from school students' perspectives. For the development of creative thinking, pre-service teachers are given opportunities to engage in divergent thinking processes through digital storytelling and interface/interaction design. Finally, pre-service teachers can develop convergent thinking in the process of choosing logical solutions to design problems.

\section{Structure and method}

This two-credit course consists of five modules: overview, literacy, design, implementation and discussion. The overview module includes the review and critique session during which pre-service teachers view and discuss various projects awarded in previous contests for software development. This module helps them start to plan their future projects in the semester. In the literacy module, the user interfaces for Flash and Actionscript are introduced for two weeks. Then participants move to design and develop their courseware individually and collaboratively for nine weeks. When pre-service teachers complete the prototype of their courseware, they conduct usability testing with their peers. In the last module, pre-service teachers learn about the concept of a robotic-based courseware, based on the IROBIQ as an educational service robot with a demonstration. Figure 3 shows a robotic demonstration designed for 5th grade elementary science, 'the change of volumes according to heat levels'. In this session, pre-service teachers are expected to actively engage in the class discussions.

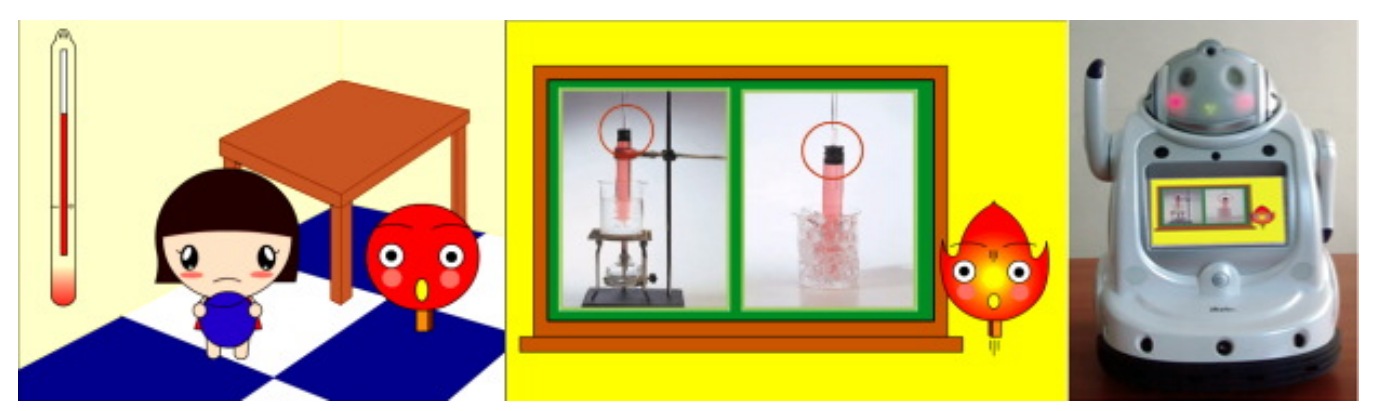

Figure 3: Screen shots of sample courseware (left) and the IROBIQ robot (right)

\section{Evaluation and lesson}

The official course evaluation of the university included 347 pre-service teachers who took this course in 2008 and 2009. The result indicated positive perceptions toward this course with mean values between 4.10 and 4.28. Participants perceived that this course was suitable to meet learner's needs for learning and thinking (Mean=4.1, SD=.94), unique contents compared to other course (Mean=4.28, $\mathrm{SD}=.88$ ), improvement of knowledge and technical skills about ICT $($ Mean=4.25, SD=.87), and satisfaction with promoting self-development (Mean=4.14, $\mathrm{SD}=.93)$.

Through this course, pre-service teachers were able to gain opportunities for creative thinking during design, logical thinking during development and programming, and divergent and convergent thinking during sharing ideas and discussions. Some preservice teachers perceived advantages in the course because of its emphasis on new types of thinking with technology and problem solving processes which are facilitating 
adaptive expertise. One pre-service teacher mentioned the following in the course evaluation:

\begin{abstract}
This course seems to go beyond the scope of computer literacy and focuses on designing instructional materials based on pedagogical knowledge and creative thinking. I designed the project with deeper thinking through discussion. And I had to consider the robotic devices as future media for content delivery.

I was interested in robotics when I saw the robot in demonstration. I had a meaningful time and experienced the fun world of computer and robotics, even though it was not easy to work very hard with my project. I guess this course can hit two birds.
\end{abstract}

On the other hand, there were some challenges as well. Due to the range of activities in the course, the pre-service teachers found it hard to follow all the course activities that included storyboarding, computer graphic handling, interaction design and programming, and the introduction of the robotic courseware during the 15-week semester. Additional challenges included the instructor's efforts for integrating cutting-edge technologies into the university course and securing budgets for purchasing robotic equipments.

\title{
Case 3: Learning by design for systems thinking
}

The last case focuses on teacher education for enhancing teachers' capacity of creating new learning environments with technologies. Literature on teacher learning shows that exemplary teachers who use ICT in meaningful ways generally adopt studentcentered learning, which requires revision or redesign of traditional lessons (Kim \& Hannafin, 2008). In this regards, this case explores the efforts of the Korea National University of Education (KNUE) toward preparing teachers for future technology-rich learning environments.

There are several courses in KNUE related to ICT in education. Particularly, Theory and Practice for Instructional Material Development and Educational Methods and Educational Technology are focusing more on ICT integration into teaching by designing and developing ICT-applied instructional materials (for details, see Kim, 2011). In continuation with these courses, the current course, Instructional Design, is offered to graduate students in both the educational technology program and in the teacher preparation program.

\section{Learning goal}

The purpose of this three-credit course is to help participants gain systematic thinking and adaptive expertise through learning by design with a system approach. Beginning teachers often gain teaching expertise through iterative teaching experiences, and their teaching practices become routines. While such routine practices tend to increase efficiency, they can hinder innovations which are required in 21st century teaching and learning (Hammerness et al., 2005; Kim \& Hannafin, 2008). Accordingly, providing preservice teachers with opportunities to think innovatively is important for enhancing their adaptive expertise. For this purpose, this course provides teachers with the opportunity to develop their systematic thinking by coordinating various components for creating new learning environments for 21st century, including curriculum, content, students, teaching and assessment methods, and technology. Designing a lesson with a system approach is essential in that future schools are likely to adopt 
flexible curriculum contents, cutting-edge technologies, and interactive activities (Kim, Park \& Koh, 2009).

\section{Structure and method}

The course activities consist of two sections: instructional systems design (ISD) and design of technology-rich learning environments. The first section focuses on instructional systems design based on behaviourism; while the second section is focusing on designing technology-rich, student-centred learning environments based on constructivism. Although the two sections are based on the different paradigms of epistemology, they share some common characteristics: a system approach for design. That is, ISD includes the systemic components and procedures for instructional development such as analysis for task, learner, and environment, design for learning objectives and instructional strategies, development for media and materials, and evaluation and revision. Sociocultural theories such as activity theory and distributed cognition also focus on a system, as a unit of analysis (Bell \& Winn, 2000), including agent, tool, activity, community, objective and their interactions.

The instructional methods of the course include lectures, topical seminars, hands-on, and project-based learning to bridge theories and practices. After the instructor's introduction and demonstration, each participant selects and leads each topical seminar. The instructor scaffolds each topical seminar leader through discussion and resources prepared for the seminar. The role of topical seminar leaders is to enable participants to deeply understand the particular theories and designed cases. The topical seminars are followed by the design projects to help students understand the complexity of the design concepts.

The first section consists of seven modules, including an introduction to ISD, systemoriented models, classroom-oriented models and product-oriented models, need analysis, task analysis, competency-based curriculum, and practice. Although systemoriented ISD is more used for military or corporate training programs to develop entire courses or curriculum than classroom lessons (Gustafson \& Branch, 2002), the systems approach of ISD is useful to understand the complexity of teaching and learning environments even in school contexts. In particular, the main idea of this section is that the instructor introduces a variety of ISD models based on different purposes and contexts, so that teachers can view ISD as a design tool, and select, adapt, and recreate appropriate ISD tools for own contexts of learning environments. Accordingly, participants are asked to design the instructional program in a non-classroom context for their design report (i.e., instructional design for the teacher training program). The participants in groups of three collaborate to complete the authentic design project based on ISD components and procedures. The modules in the first section are designed to help participants develop an epistemic view on instructional design with a system approach in terms of understanding the complexity of instructional design components and procedures. Based on such fundamental understanding, participants move on to design technology-rich learning environments; they are based on constructivist theories and contexts.

The second section, design of technology-rich learning environment, consists of five modules, including an introduction to constructivist learning environments, design of constructivist learning environments, activity theory-based design, distributed cognition-based design, and grounded design. In this section, participants learn about the nature and application of particular theories such as activity theory and distributed 
cognition that guide the design and the development of technology-rich learning environments in more comprehensive and systemic ways. At the end of the section, participants are asked to complete the design report that delineates how to design technology-rich learning environments based on constructivist approaches. Although the second section allows participants to work with their familiar subject matter, the design approach is not familiar to them; participants are supposed to analyse learners, learning processes, technology, and interaction between them in an in-depth manner. The final design report should present not only a technology-rich lesson plan, but also a comprehensive learning environment, including educational problem statement, theoretical design framework, technology, design procedure, and lesson plan.

\section{Evaluation and lesson}

After the first section, the instructor administered the questionnaire to understand the nine participants' reactions to the ISD activities. The questions include participants' perceptions toward instructional design experiences for designing technology-rich environments during their pre-service teacher training and their experiences of completing the ISD design report in this course, including both positive and negative experiences.

Regarding participants' perceptions for instructional design with a system approach, all participants indicated their difficulties in completing instructional design for unfamiliar contexts. On the other hand, through this learning experience, the participants could develop an epistemic view and attitude toward design perspectives which include systems thinking and adaptive expertise. For instance, one participant reported the following regarding his design experience in unfamiliar contexts:

\footnotetext{
It [instructional design for the teacher training program] is not necessarily to know as a teacher. However, I was able to develop the competency both as a teacher and an instructional designer when I participated in projects related to teacher support, learning environments, and system construction in the comprehensive educational context (e.g., development of instructional materials, training teachers).
}

Participants also reported several positive perceptions such as collaborative design experiences for the first ISD project, the development of new perspectives for instructional design in non-classroom settings, positive learning experiences about detailed components and procedures of instructional design, the development of a sense of design aspects, and hands-on experiences in the authentic project context.

In the second section, the participants' draft design reports did not represent comprehensive learning environments well; the technology-rich lesson plans lack support from in-depth analysis. The instructor gave feedback on the draft and the participants submitted the revised reports. Participants' revised reports indicated how they were using systems thinking by aligning problems, theories, and technology. For example, one participant identified the educational problem in mathematics education as mathematical anxiety. To solve this problem, she adopted situated learning and realistic mathematics education as grounding theory and wiki-based collaboration as technology and pedagogy. She redesigned existing classroom-based mathematics lessons into a wiki-based learning environment.

On the other hand, the participants had asked for various design cases to better understand the complexity of design processes. Building on this learning experience, 
the participants may take another advanced course, Emerging Learning Environment Design II, in the following semester to apply and expand their systems thinking and adaptive expertise in creating technology-rich learning environments.

\section{Characterising new approaches for enhancing teachers' ICT capacity}

In this section, we characterise the new approaches to teacher education for 21st century learning environments by comparing and contrasting the three cases to better understand some essential features across different contexts of teacher education. Table 1 summarises the characteristics of the three cases as new approaches to teacher education for enhancing ICT capacity in 21st century learning environments, along with the general information about the courses such as course titles, target audience, offering types, credit hours, learning goals, etc.

Table 1: Characterising the new approaches to teacher education with three cases

\begin{tabular}{|c|c|c|c|}
\hline Component & Case 1 & Case 2 & Case 3 \\
\hline Course title & Computer Practice & $\begin{array}{l}\text { Web-based CourseWare } \\
\text { Development and } \\
\text { Programming }\end{array}$ & Instructional Design \\
\hline $\begin{array}{l}\text { Target } \\
\text { audience }\end{array}$ & All students & All students & $\begin{array}{l}\text { Educational technology } \\
\text { students, but not limited to }\end{array}$ \\
\hline Type & Compulsory & Compulsory & Elective \\
\hline Credit & 1 credit & 2 credits & 3 credits \\
\hline $\begin{array}{l}\text { Learning } \\
\text { goal }\end{array}$ & $\begin{array}{l}\text { Computational thinking, } \\
\text { creative thinking }\end{array}$ & $\begin{array}{l}\text { Logical, convergent and } \\
\text { divergent thinking }\end{array}$ & $\begin{array}{l}\text { Instructional design ability, } \\
\text { systems thinking }\end{array}$ \\
\hline Topic & $\begin{array}{l}\text { Creating animations, } \\
\text { games, digital stories, etc. } \\
\text { Programming concepts }\end{array}$ & $\begin{array}{l}\text { Creating web courseware } \\
\text { for elementary school } \\
\text { lessons }\end{array}$ & $\begin{array}{l}\text { Instructional systems } \\
\text { design and technology rich } \\
\text { learning environment } \\
\text { design }\end{array}$ \\
\hline $\begin{array}{l}\text { Instruc- } \\
\text { tional } \\
\text { method }\end{array}$ & $\begin{array}{l}\text { Practice, collaborative and } \\
\text { individual projects }\end{array}$ & $\begin{array}{l}\text { Lecture, practice, } \\
\text { discussion, individual } \\
\text { projects. }\end{array}$ & $\begin{array}{l}\text { Seminar, practice, and } \\
\text { collaborative and } \\
\text { individual project }\end{array}$ \\
\hline $\begin{array}{l}\text { Success } \\
\text { factor }\end{array}$ & $\begin{array}{l}\text { Focusing on thinking skills } \\
\text { rather than programming } \\
\text { syntax; fostering critical } \\
\text { thinking in integrating } \\
\text { various media for } \\
\text { educational purposes }\end{array}$ & $\begin{array}{l}\text { Thinking as a producer not } \\
\text { a consumer for web } \\
\text { courseware; discussing } \\
\text { and sharing creative } \\
\text { projects }\end{array}$ & $\begin{array}{l}\text { Providing unfamiliar } \\
\text { situations as design topics } \\
\text { and approaches to increase } \\
\text { systems thinking; } \\
\text { providing consistent focus } \\
\text { - systems design across } \\
\text { different epistemological } \\
\text { perspectives }\end{array}$ \\
\hline $\begin{array}{l}\text { Lessons } \\
\text { learned }\end{array}$ & $\begin{array}{l}\text { Scaffolding strategies are } \\
\text { required to stimulate } \\
\text { learners' thinking } \\
\text { processes to pursue } \\
\text { increasingly complex } \\
\text { projects }\end{array}$ & $\begin{array}{l}\text { Sharing divergent thinking } \\
\text { via usability and learning } \\
\text { interaction for the best web } \\
\text { courseware are needed }\end{array}$ & $\begin{array}{l}\text { Various design cases are } \\
\text { needed to understand the } \\
\text { complex concepts of } \\
\text { systems design }\end{array}$ \\
\hline
\end{tabular}

Learning goals

The learning goals of three cases focus more on enhancing teachers' thinking skills by learning both ICT education (i.e., learning about ICT) and ICT in education (i.e., learning with ICT). The learning goals also include the development of knowledge and skills in subjects such as programming or authoring tools and instructional design. For 
example, Cases 1 and 2 emphasise the importance of teachers' creative thinking during the process of developing ICT-based materials while Case 3 emphasises the importance of systems thinking in instructional design and development. Because the course topics and activities in Cases 1 and 2 focus more on the development of lesson materials with emerging technologies, it is essential for pre-service teachers to develop creative, computational and logical thinking. On the other hand, the learning goal in Case 3 focuses more on developing learning environments based on systems thinking where teachers view teaching and learning as complex systems.

Ultimately, all three cases aim to help pre-service teachers develop adaptive expertise, which is essential for the next generation of teachers to be prepared in a changing world. As mentioned earlier, adaptive expertise includes two dimensions - efficiency and innovation (Hammerness et al., 2005). In all three cases, the efficiency dimension was increased when pre-service teachers were asked to complete their authentic projects within a certain time frame. Because authentic projects often involve complexities and unexpected failures, students can have opportunities to practise time management with reasonable timeframes, efforts, and cost for productive outcomes. Through the repeated design experiences in multiple projects, participants increased their efficiency by managing complexities. The innovation dimension of teachers' adaptive expertise can be enhanced when they develop new perspectives on technology and pedagogy during the process of completing their course projects. Because all three cases involved cutting-edge technologies or innovative pedagogical ideas for developing lesson plans and lesson materials, participating teachers were expected to integrate content and technologies in innovative ways.

\section{Topics}

The course topics in the three cases focus on design and development of lessons and instructional materials with technology. The topics in Cases 1 and 2 are related to computer programming while Case 3 is related to instructional design. Particularly, because Cases 1 and 2 involve cutting-edge technologies, pre-service teachers could understand how new technologies make teaching and learning more innovative in the changing world. Case 3 situated teachers in unfamiliar contexts in terms of content and design approaches for instructional design so that teachers could understand the meaning of systems design.

\section{Instructional methods}

The instructional methods in the three cases were comprehensive, to bridge the gap between theory and practice. That is, the courses were designed to provide lectures on theories and cases, followed by authentic projects that require the integration of theory and practice. This approach around the nexus of theory and practice is consistent with the teacher education literature, emphasising the importance of situated learning with authentic projects in teaching contexts (Kim \& Hannafin, 2008).

The instructional methods in Cases 1 and 2 present interesting approaches: Immersing first, applying later. For example, because the focus of the course was on developing lesson materials with Scratch which school students will use as a learning tool, preservice teachers needed to immerse themselves into this learning tool from school students' perspectives. After learning Scratch for creative thinking, pre-service teachers can better understand their future students' motivation and difficulties and prepare their lesson materials accordingly. 
Case-based learning (e.g., case methods) is useful in teacher education situations where it is difficult to understand complex and innovative ideas (Kim, 2011). Accordingly, Case 2 used concrete cases for reviewing project work done by previous students, and for better understanding of the role of emerging technology such as robots in education. The pre-service teachers' critiques on the projects by previous students made them anticipate and plan their course projects better. Also, it is effective to use multiple authentic cases for demonstrating and discussing the affordances of robots (e.g., IROBIQ) in educational contexts, because new concepts and ideas can be strengthened via concrete cases.

\section{Success factors and lessons learned}

All three cases present some extent of trials and errors during implementation of the courses. However, success factors involve several characteristics of the new approaches to teacher education. First, focusing on thinking skills rather than technical skills and theoretical knowledge, and supporting teachers to think differently and relearn new perspectives beyond their previous experience. Second, providing various contexts, such as various media in Case 1, and different epistemological perspectives and practices in Case 3, is useful for enhancing thinking skills, such as critical thinking and systems thinking, and, more importantly, adaptive expertise. Since the learning goals toward the development of thinking skills are complex with multiple dimensions, they are not easily understood from the single perspective and tool (Spiro, Feltovich, Jacobson \& Coulson, 1992). Instead, various media and perspectives in the cases were used to integrate complex concepts of topics, and further to facilitate the development of the desired thinking skills. Third, providing new roles to teachers is effective in making them aware of the challenges and potentials in new environments, and willing to apply innovative ideas. That is, following routines represents efficiency, but having a habit of reflection is likely to lead innovation (Hammerness et al, 2005; Kim \& Hannafin, 2008). For instance, the instructor in Case 2 encouraged participants to think of themselves as producers, not simply consumers (or implementers) of web courseware. Similarly, the projects in Case 3 enabled participants to take a role as instructional designers. This presented a different design situation, where the designed educational programs will be used by other instructors that the instructional designer may not know. This situation is different from classroom lesson plans that teachers often design and develop lessons for their own classes, where they view themselves as implementers rather than designers.

On the other hand, the three cases present different lessons learned from the experiences of designing and enacting new curriculum. First, while all cases adopted comprehensive, authentic projects with new approaches, such as the development of materials with cutting-edge technologies and instructional design in unfamiliar situations, the projects also demanded higher workloads than other typical classes. Although participants acknowledged the positive effects of the courses in Cases 2 and 3 , they also felt it was difficult to complete the projects. Motivating teachers is essential to make them understand why they learn, and engage them in meaningful course projects (Kolodner \& Guzdial, 2000). Second, providing scaffolding strategies is needed to facilitate teachers' thinking processes during complex projects such as Case 1 mentioned above. Similarly, in the other graduate course of Case 3, participants said that they needed some cases as scaffolds to learn from other experiences. Lastly, undergraduate courses in Cases 1 and 2 present institutional support; the courses are compulsory for all pre-service teachers. That leads to larger impacts on broader audiences from the various departments so that many next generation teachers can 
learn innovative teaching practices during their preparation programs. This universitylevel implementation is impossible without institutional support. Also, because innovative approaches to teacher education often involve hands-on activities, traditional evaluation methods such as paper and pencil tests and relative evaluation are difficult in relation to assessing teachers' learning holistically. Instead, performance-based evaluation and criterion-referenced evaluation are recommended as new evaluation methods.

\section{Conclusion}

The goal of this paper is to introduce and discuss three cases of teacher education in Korea as new approaches to 21st century learning environments, and to analyse what features of the teacher education cases may be characterised as new approaches. In this paper, Cases 1 and 3 exemplify that ICT is viewed as a mediating tool for teachers to learn a set of thinking skills and beliefs, such as computational, creative, or systems thinking, which comprise the fundamental skills that they need to possess in order to be adaptable in the emerging complexity of current educational landscape. Case 2 shows the possibility of broadening the traditional conception of ICT with the illustration of teachers developing a capacity to learn cutting-edge technologies like robotics, for convergent and divergent thinking, and how such preparation helps teachers better understand both the potential and challenges of teaching and learning in future environments. All the three cases elucidate our point that building the ICT capacity for the next generation of teachers requires us to revisit our underlying assumptions on the role of ICT for education and to reconsider the design of ICT training modules consistent with our epistemic view.

We conclude by addressing two limitations and then suggest future research directions. Firstly, the selection of three cases was purposive since we aimed to select and analyse cases that revealed the research phenomenon, which was to unpack the making of more innovative approaches to ICT courses in teacher education contexts. We understood the inherent limitations associated with purposive sampling in terms of generalisability and credibility. Since the authors were also the instructors in the three courses discussed in the paper, some cautions should be made in terms of generalising the findings. However, we believe that the present study surfaced important issues in teachers' ICT capacity building and teacher training models, and such issues could be further sought in-depth in future research studies that involve a larger number of cases and multiple sources of data. Lastly, this paper is the starting point to briefly explore new approaches to teacher education for 21st century learning environments. For further studies, it will be necessary to examine learning processes and outcomes of pre-service and in-service teachers more in-depth. Also, it is important to examine closely what theoretical underpinnings support and explain these approaches to teacher education, so that teacher educators and researchers can understand and verify new approaches for new environments.

\section{Acknowledgments}

We wish to thank Sunghwan Gu and Wookyung Shim (Figure 1), Sulee Kang and Yuna Yim (Figure 2), and Minjung Lee (Figure 3) for sharing their projects used in this paper. 


\section{References}

Bell, P. \& Winn, W. (2000). Distributed cognitions, by nature and design. In D. Jonassen \& S. M. Land (Eds.), Theoretical foundations of learning environments (pp. 123-145). New Jersey: Lawrence Erlbaum Associates.

Bransford, J. D., Brown, A. L. \& Cocking, R. R. (Eds) (2000). How people learn: Brain, mind, experience and school. Expanded edition. Washington DC: National Academies Press, 2000. http: / / www.nap.edu / openbook.php?isbn=0309070368

Bransford, J. D. \& Schwartz, D. L. (1999). Rethinking transfer: A simple proposal with multiple implications. Review of Research in Education, 24(1), 61-101. http: / / dx.doi.org/10.3102/0091732X024001061

Gustafson, K. L. \& Branch, R. M. (2002). Survey of instructional development models (4th ed.). ERIC Clearing House on Information \& Technology. Syracuse, NY: Syracuse University. http:/ / www.eric.ed.gov/ERICWebPortal/ contentdelivery/servlet/ERICServlet?accno=ED477517

Hammerness, K., Darling-Hammond, L. \& Bransford, J. (2005). How teachers learn and develop. In L. Darling-Hammond \& J. Bransford (Eds.), Preparing teachers for a changing world (pp. 358389). San Francisco: Jossey-Bass.

Han, J. (2010). Robot-aided learning and r-learning services. In D. Chugo (Ed.), Human-robot interaction (pp. 247-266). InTech. http: / / www.intechopen.com/books/ human-robotinteraction/ robot-aided-learning-and-r-learning-services [viewed 12 Dec 2011].

Hatano, G. \& Inagaki, K. (1986). Two courses of expertise. In H. Stevenson, H. Azuma \& K. Hakuta (Eds.), Child development and education in Japan. New York: Freeman.

Hur, Y., Choi, M. \& Han, J. (2009). Make your own robots to play and learn with! Robot-based instruction program in Korea. Proceedings of the 18th IEEE International Symposium on Robot and Human Interactive Communication, Toyama, Japan, Sept. 27-Oct. 2, 2009. http:/ / dx.doi.org/10.1109/ROMAN.2009.5326276

Hwang, D., Yang, H. \& Kim, H. (2010). E-learning in the Republic of Korea. UNESCO Institute for Information Technologies in Education. Russia: The Russian Federation. http: / / ru.iite.unesco.org/pics / publications/ en/ files/3214677.pdf

Kim, H. (2011). Exploring freshmen pre-service teachers' situated knowledge in reflective reports during case-based activities. The Internet and Higher Education, 14(1), 10-14. http: / / dx.doi.org/10.1016/j.iheduc.2010.03.005

Kim, H. \& Hannafin, M. J. (2008). Situated case-based knowledge: An emerging framework for prospective teacher learning. Teaching and Teacher Education, 24(7), 1837-1845. http: / / dx.doi.org/10.1016/j.tate.2008.02.025

Kim, H. Park, I. \& Koh, B. (2009). Study on forecasting the future of technology in education of Korea. KR2001-12. Korea Education \& Research Information Service: Seoul, Korea.

Klassner, F. \& Anderson, S. D. (2003). LEGO MindStorms: Not just for K-12 anymore. IEEE Robotics $\mathcal{E}$ Automation Magazine, 10(2), 12-18. http:/ / dx.doi.org/10.1109/MRA.2003.1213611

Kolodner, J. L. \& Guzdial, M. (2000). Theory and practice of case-based learning aids. In D. H. Jonassen \& S. M. Land (Eds.), Theoretical foundations of learning environments (pp. 215-242). Mahwah, NJ: L. Erlbaum Associates.

Lortie, D. (1975). School teacher: A sociological study. London: University of Chicago Press.

MEST (2011). Implementation plans for smart learning: The way to the country of talents. Report presented at The open policy forum of Ministry of Education, Science and Technology (MEST), Seoul, Korea. 
MIT Media Lab (2012). Scratch. http: / / scratch.mit.edu/ [viewed 8 Feb 2012].

Papert, S. (1980). Mindstorms: Children, computers, and powerful ideas. New York: Basic Books.

Park, S., Jun, W. \& Kim, H. (2011). The analyses and improvement plans for computer curriculum in universities of education. Korean Association of Information Education: Seoul, Korea.

Resnick, M. (2007). Sowing the seeds for a more creative society. Learning and Leading with Technology, 35(4), 18-22. http:/ / web.media.mit.edu/ mres/papers / Learning-Leading.pdf

Resnick, M., Maloney, J., Monroy-Hernandez, A., Rusk, N., Eastmond, E., Brennan, K., Millner, A., Rosenbaum, E., Silver, J., Silverman, B. \& Kafai, Y. (2009). Scratch: Programming for all. Communications of the ACM, 52(11), 60-67. http:/ / dx.doi.org/10.1145/1592761.1592779; also at http:// web.media.mit.edu/ mres/papers/Scratch-CACM-final.pdf

Schön, D. (1983). The reflective practitioner. Basic Books: New York.

So, H. J. \& Kim, B. (2009). Learning about problem-based learning: Student teachers integrating technology, pedagogy, and content knowledge. Australasian Journal of Educational Technology, 25(1), 101-116. http:/ / www.ascilite.org.au/ajet/ajet25/ so.html

Spiro, R. J., Feltovich, P. J., Jacobson, M. J. \& Coulson, R. L. (1992). Cognitive flexibility, constructivism, and hypertext: Random access instruction for advanced knowledge acquisition in ill-structured domains. In T. M. Duffy \& D. H. Jonassen (Eds.), Constructivism and the technology of instruction: A conversation (pp. 57-75). Hillsdale, New Jersey: Lawrence Erlbaum Associates, Publishers.

Wing, J. M. (2006). Computational thinking. Communications of the ACM, 49(3), 33-35. http: / / dx.doi.org/10.1145/1118178.1118215; also at http: / / www.cs.cmu.edu / wing/ publications / Wing06.pdf

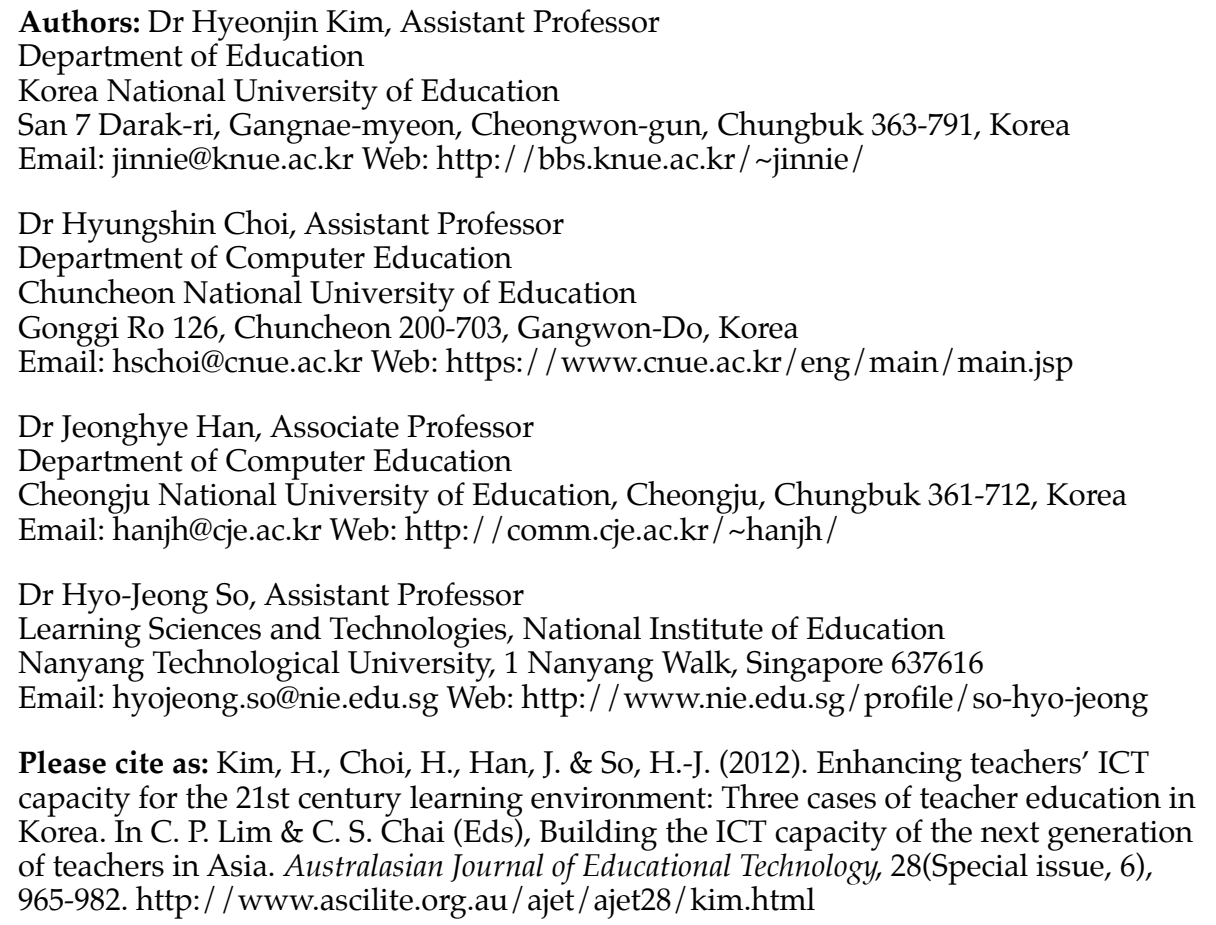

